\title{
A theoretical model on the formation mechanism and kinetics of highly toxic air pollutants from halogenated formaldehydes reacted with halogen atoms
}

\author{
Y. M. Ji ${ }^{1}$, H. H. Wang ${ }^{1,2}$, Y. P. Gao ${ }^{1,2}$, G. Y. Li ${ }^{1}$, and T. C. An ${ }^{1}$ \\ ${ }^{1}$ State Key Laboratory of Organic Geochemistry and Guangdong Key Laboratory of Environmental Resources Utilization and \\ Protection, Guangzhou Institute of Geochemistry, Chinese Academy of Sciences, Guangzhou 510640, China \\ ${ }^{2}$ University of Chinese Academy of Sciences, Beijing 100049, China \\ Correspondence to: T. C. An (antc99@ gig.ac.cn)
}

Received: 26 March 2013 - Published in Atmos. Chem. Phys. Discuss.: 9 July 2013

Revised: 29 September 2013 - Accepted: 7 October 2013 - Published: 21 November 2013

\begin{abstract}
The atmospheric reactions of halogenated formaldehydes with halogen atoms were investigated by high-accuracy molecular orbital calculation. Our studies showed that compared to $\mathrm{X}$-addition pathway, the $\mathrm{H}$ abstraction pathway was demonstrated to be more preferred to form halogenated formyl radicals and hydrogen halides (HX). In specific areas with abundant halogen atoms, such as the marine boundary layer (MBL), halogenated formyl radical was reacted easily with halogen atoms and finally transformed into $\mathrm{HX}$ and $\mathrm{CO}_{2}$ in the presence of water; otherwise, this radical was degraded to $\mathrm{CO}_{2}$, halogen gas, and halogenated oxide in the presence of $\mathrm{O}_{2}$ and halogen atoms. By using the canonical variational transition state theory, the kinetics calculations were performed within a wide atmospheric temperature range of 200-368 K, and theoretical values agreed well with the available experimental data. Under atmospheric conditions, rate constants decreased as altitude increased, and especially the rate constants of halogen atoms reacted with FCHO quickly reduced. The kinetic results showed that although the reactions of halogenated formaldehydes with $\mathrm{F}$ atoms occurred more easily than did those with $\mathrm{Cl}$ and $\mathrm{Br}$ atoms, the two latter reactions were still important atmospheric degradation process, especially in the MBL. The modified Arrhenius equations of rate constants within the atmospheric temperature range were fitted, which helped to understand the established atmospheric model and estimated the contribution of title reactions to atmospheric chemistry pollution.
\end{abstract}

\section{Introduction}

The Antarctic-like ozone hole was proposed in the Arctic in the 2011 Nature paper (Manney et al., 2011). This proposal indicated that the implementation of the Montreal Protocol did not well restrain chlorofluorocarbons (CFCs) and hydrochlorofluorocarbons (HCFCs) to destroy the ozone and increase the stratospheric halogen loading (Manney et al., 2011; Newman et al., 2009) despite very low anthropogenic emission of CFCs, HCFCs and halogen (Manney et al., 1994; Newman et al., 2009). Halogenated formaldehydes are one of the halogenated molecules in the atmosphere, and are reactive molecules to form the atmospheric degradation intermediates of several halocarbons such as CFCs and HCFCs (Hasson et al., 1998; Sanhueza et al., 1975; Wallington et al., 1992) as well as from the tropospheric reactions of halogen atoms with volatile organic compounds (VOCs) such as isoprene (Fantechi et al., 1998). On the other hand, halogen species, such as chlorine and bromine, play an important role in the atmospheric chemical processes. Apart from anthropogenic organohalogen source, another important sources is from sea-salt aerosols (Finlayson-Pitts, 2003) and the heterogeneous reactions on these aerosol surfaces (Rossi, 2003). Thus, abundant halogen species could be frequently found in the marine boundary layers (MBL) (Sommariva et al., 2012; Wingenter et al., 2005). Moreover, these halogen species are reactive toward various VOCs as well as ozone (Foster et al., 2001; Ofner et al., 2012; Riedel et al., 2012). Especially in occurrences of the depletion of surface ozone in the Atlantic and Arctic, the presence of abundant halogen atoms has been 
proven (Jobson et al., 1994; Read et al., 2008; Solberg et al., 1996). Thus, as a prelude to understand the role of VOCs in the atmospheric transformation, the atmospheric reactions of halogenated formaldehydes with halogen atoms are expected to be a significant process in some particular areas such as MBL.

So far, some of the atmospheric reactions of three halogenated formaldehydes ( $\mathrm{FCHO}, \mathrm{ClCHO}$ and $\mathrm{BrCHO}$ ) with three halogen atoms $(\mathrm{F}, \mathrm{Cl}$ and $\mathrm{Br})$, have been investigated experimentally: FCHO +F (Behr et al., 1993, 1998; Francisco et al., 1990; Hasson et al., 1998; Meagher et al., 1997), $\mathrm{FCHO}+\mathrm{Cl}$ (Bednarek et al., 1996; Edney et al., 1992; Meagher et al., 1997; Wallington et al., 1992), and $\mathrm{ClCHO}+\mathrm{Cl}$ (Catoire et al., 1996; Libuda et al., 1990; Orlando, 1999; Sanhueza et al., 1975; Wallington et al., 1996). However, these experimental studies only focused on the kinetics data, and never involved in the reaction mechanisms. Nevertheless, to understand the transformation mechanisms and fate of atmospheric reaction intermediates (IM) is an indispensable component to assess the risk of various toxic VOCs (Blotevogel et al., 2010). As for the theoretical studies, only limited published data was reported on the reactions of FCHO + F (Francisco et al., 1990; Wu et al., 2003) and $\mathrm{FCHO}+\mathrm{Cl}$ (Wu et al., 2002), and these studies achieved different conclusions regarding the contribution of addition pathways. For instance, the result obtained by Francisco et al. (1990) concluded that addition of fluorine atom onto FCHO was competitive, which contradicted the results of Wu et al. (2003). Furthermore, no studies on the kinetic data of the addition pathways have been conducted by these theoretical researchers. To our knowledge, no experimental or theoretical investigations have been reported on the title reactions, except the $\mathrm{ClCHO}+\mathrm{Cl}$ and $\mathrm{FCHO}+\mathrm{F} / \mathrm{Cl}$ reactions. Thus, to gain insight into the environmental impact of halogenated formaldehydes, a systematic theoretical study is required to illustrate the detailed atmospheric reaction mechanisms and kinetics of the title reactions, and the potential importance of the title reactions as an atmospheric degradation pathway is also necessary to qualitatively investigate with a theoretical calculation method.

In this study, the atmospheric reaction mechanisms and kinetics of halogenated formaldehydes reaction with halogen atoms were investigated using the dual-level direct dynamics (DLD) method. The temperature-dependent rate constants of the title reactions in atmospheric environment were deduced using canonical variational transition state theory (CVT) with small curvature tunneling (SCT) to simulate the troposphere temperature range within the atmospheric temperature range of 200-368 K. Furthermore, the calculated data were compared with the available experimental results to assess the reliability of the proposed model.

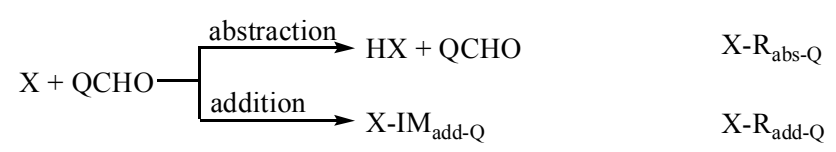

Scheme 1. Possible pathways for the title atmospheric reactions, where QCHO represents the halogenated formaldehydes as well as $\mathrm{Q}=\mathrm{F}, \mathrm{Cl}$, and $\mathrm{Br}$. $\mathrm{X}$ represents the halogen atoms as well as $\mathrm{X}=\mathrm{F}$, $\mathrm{Cl}$, and $\mathrm{Br}$.

\section{Methods}

All quantum chemistry and computational kinetics were calculated with Gaussian 03 program (Frisch et al., 2003) and Polyrate 9.4.1 program (Corchado et al., 2002), respectively. Geometric parameters and frequency calculations were carried out at the PMP2/6-311+G(d,p) level. The vibrational frequencies were performed to characterize the nature of each point on the potential energy surface (PES) and make zero-point-energy (ZPE) corrections. Using the intrinsic reaction coordinate (IRC) theory, the minimum-energy path (MEP) was constructed to verify that each transition state (TS) uniquely connected the designated reactants with the products. The DLD method (Hu et al., 1996; Truhlar et al., 1996) was employed to investigate the reaction mechanisms and kinetics. The energy profiles of the title atmospheric reactions were refined at the high-accuracy QCISD(T)/6$311+\mathrm{G}(2 \mathrm{df}, 2 \mathrm{p})$ level based on the geometries mentioned above. For simplicity, a double slash " "//" was used to denote the dual-level dynamics approach such as QCISD(T)//PMP2. Based on the aforementioned results of quantum chemistry calculations, the products distributions and the rate constants of all the possible reaction pathways were computed using CVT (Truhlar et al., 1980) plus SCT (Liu et al., 1993).

\section{Results and discussion}

\subsection{Atmospheric reaction mechanism}

Generally, two different attack sites were present on the halogenated formaldehydes ( $\mathrm{QCHO}, \mathrm{Q}=\mathrm{F}, \mathrm{Cl}$, and $\mathrm{Br}$ ) by halogen atoms $(\mathrm{X}=\mathrm{F}, \mathrm{Cl}$, and $\mathrm{Br})$ : the $\mathrm{H}$ atom was abstracted from the carbonyl group position $\left(\mathrm{X}-\mathrm{R}_{\mathrm{abs}-\mathrm{Q}}\right)$ and the halogen atom was added onto the carbon atom of carbonyl group $\left(\mathrm{X}-\mathrm{R}_{\mathrm{add}-\mathrm{Q}}\right)$ (Scheme 1). Figures $\mathrm{S} 1$ and $\mathrm{S} 2$ illustrated the geometries of reactants, products, TSs, complexes, and IMs calculated at the MP2/6-311G(d,p) level. To confirm the calculated geometry corresponding to a saddle point with only one imaginary frequency or a local minimum without imaginary frequency; the harmonic vibrational frequencies of the main stationary points were also listed in Table S1. The energy parameters were also presented in Table 1, including the reaction enthalpies with heat corrections $\left(\Delta \mathrm{H}_{298}^{0}\right)$ and potential barrier heights with ZPE correction $(\Delta E)$ obtained 
Table 1. Energy parameters, including the potential barrier heights $(\Delta E)$, reaction enthalpies $\left(\Delta \mathrm{H}_{298}^{0}\right)$, and dissociation energies $\left[\mathrm{D}_{298}^{0}\right.$ $(\mathrm{C}-\mathrm{H})$ ] for the title reactions $\mathrm{QCHO}+\mathrm{X} \rightarrow$ products (in $\mathrm{kcal} \mathrm{mol}^{-1}$ ).

\begin{tabular}{|c|c|c|c|c|c|c|c|}
\hline \multirow[t]{2}{*}{$\mathrm{X}$} & \multicolumn{2}{|r|}{$\mathrm{F}$} & \multicolumn{2}{|r|}{$\mathrm{Cl}$} & \multicolumn{2}{|r|}{$\mathrm{Br}$} & \multirow{2}{*}{$D_{298}^{0}(\mathrm{C}-\mathrm{H})$} \\
\hline & $\Delta E$ & $\Delta \mathrm{H}_{298}^{0}$ & $\Delta E$ & $\Delta \mathrm{H}_{298}^{0}$ & $\Delta E$ & $\Delta \mathrm{H}_{298}^{0}$ & \\
\hline QCHO & \multicolumn{7}{|c|}{ H-abstraction pathways } \\
\hline FCHO & -2.68 & $-33.94 *(-35.14)$ & 5.79 & $-0.59^{*}(-2.15)$ & 14.57 & $12.05 *(13.63)$ & 97.71 \\
\hline $\mathrm{ClCHO}$ & -4.98 & -43.33 & -0.58 & -10.05 & 5.70 & 2.58 & 87.61 \\
\hline $\mathrm{BrCHO}$ & -5.75 & -48.18 & -1.81 & -14.91 & 2.38 & -2.26 & 82.74 \\
\hline QCHO & \multicolumn{7}{|c|}{ OH-addition pathways } \\
\hline FCHO & 5.70 & -23.62 & 14.19 & 13.07 & 19.38 & 22.15 & \\
\hline $\mathrm{ClCHO}$ & 7.38 & -24.32 & 14.27 & 18.70 & 18.43 & 20.98 & \\
\hline $\mathrm{BrCHO}$ & 7.60 & -21.74 & 14.02 & 8.08 & 17.89 & 20.32 & \\
\hline
\end{tabular}

* Experimental value (NIST).

at the QCISD(T)/6-311+G(2df,2p)//PMP2/6-311+G(d,p) level. All geometries optimized at the PMP2/6-311+G(d,p) level and all energies obtained at the QCISD(T)//PMP2 level agreed with the available experimental data (Groner et al., 2001; Huisman et al., 1979; Nagai et al., 1981; NIST). The maximum relative errors were less than $0.01 \%$ and $1.7 \mathrm{kcal} \mathrm{mol}^{-1}$ for the geometric parameters and energy parameters, respectively.

\subsubsection{H-abstraction pathways}

To compare the earliness of $\mathrm{H}$-abstraction TS structures, a geometry parameter $\mathrm{L}$ was calculated using the variation in the breaking bond distance between TSs and reactants $(\delta(\mathrm{C}-$ $\mathrm{H})$ ) as well as the forming bond distance between TSs and products $(\delta(\mathrm{H}-\mathrm{X})): \mathrm{L}=\delta(\mathrm{C}-\mathrm{H}) / \delta(\mathrm{H}-\mathrm{X})$ (Table $\mathrm{S} 2)$. This parameter L denoted not only a TS structure associated with a reactant-like or a product-like ( $\mathrm{L}<1$ or $\mathrm{L}>1)$ character, but also the quantification of the corresponding trend (Rayez et al., 1994). As shown in Table 1, except for Br- $\mathrm{R}_{\text {abs-F }}$ and $\mathrm{Br}-$ $\mathrm{R}_{\mathrm{abs}-\mathrm{Cl}}$ pathways $(\mathrm{L}>1)$, all other pathways were exothermic reactions $(\mathrm{L}<1)$. That is, the reaction pathways with TS having a reactant-like character $(\mathrm{L}<1)$ were exothermic reactions. Otherwise, it was expected to be endothermic. This conclusion was in accordance with the Hammond postulate (Hammond, 1955); in addition, a positive correlation was observed between $\mathrm{L}$ and $\Delta \mathrm{H}_{298}^{0}$ : the lowest (highest) value of $\mathrm{L}$ corresponded to the lowest (highest) value of $\Delta \mathrm{H}_{298}^{0}$. For instance, the minimum (0.07) and maximum (1.42) L values of F- $\mathrm{R}_{\text {abs-Br }}$ and Br- $\mathrm{R}_{\text {abs-F }}$ pathways (Table $\mathrm{S} 2$ ) corresponded to the lowest and the highest $\Delta \mathrm{H}_{298}^{0}$ with $-48.18 \mathrm{kcal} \mathrm{mol}^{-1}$ and $12.05 \mathrm{kcal} \mathrm{mol}^{-1}$, respectively (Table 1 ). For the attack of $\mathrm{F}$ atoms to three halogenated formaldehydes, the $\Delta E \mathrm{~s}$ of $\mathrm{H}$-abstraction pathways were $-2.68 \mathrm{kcal} \mathrm{mol}^{-1}$ for $\mathrm{F}-\mathrm{R}_{\mathrm{abs}-\mathrm{F}},-4.98 \mathrm{kcal} \mathrm{mol}^{-1}$ for $\mathrm{F}-\mathrm{R}_{\mathrm{abs}-\mathrm{Cl}}$, and -5.75 $\mathrm{kcal} \mathrm{mol}^{-1}$ for $\mathrm{F}-\mathrm{R}_{\mathrm{abs}-\mathrm{Br}}$, decreasing with the order of $\Delta E\left(\mathrm{~F}-\mathrm{R}_{\mathrm{abs}-\mathrm{F}}\right)>\Delta E\left(\mathrm{~F}-\mathrm{R}_{\mathrm{abs}-\mathrm{Cl}}\right)>\Delta E\left(\mathrm{~F}-\mathrm{R}_{\mathrm{abs}-\mathrm{Br}}\right)$. This result indicated that the $\mathrm{H}$ atom of halogenated formaldehy- des should be abstracted more easily from $\mathrm{FCHO}$ to $\mathrm{ClCHO}$ to $\mathrm{BrCHO}$. To further investigate the reactivity of $\mathrm{H}$ atom, the $\mathrm{C}-\mathrm{H}$ bond-dissociation energies $\left(\mathrm{D}_{298}^{0}(\mathrm{C}-\mathrm{H})\right)$ in carbonyl group were calculated, and the results were also listed in Table 1. For the three halogenated formaldehydes, the corresponding $\mathrm{D}_{298}^{0}(\mathrm{C}-\mathrm{H})$ values were $97.71,87.61$, and $82.74 \mathrm{kcal} \mathrm{mol}^{-1}$. This result was in line with the order of the $\Delta E$, indicating that the halogen atom substitutions from $\mathrm{F}$ to $\mathrm{Cl}$ to $\mathrm{Br}$ atom can increase the reactivity of $\mathrm{H}$ atom. The reaction enthalpies obtained were $-33.94\left(\mathrm{~F}-\mathrm{R}_{\mathrm{abs}-\mathrm{F}}\right)$, -43.33 (F-R $\mathrm{R}_{\mathrm{abs}-\mathrm{Cl}}$ ), and -48.18 (F-R $\mathrm{abs-Br}$ ) kcal $\mathrm{mol}^{-1}$, exhibiting the same trend as that of potential barrier heights. Similar conclusions can be drawn regarding different halogenated formaldehydes reaction with $\mathrm{Cl}$ and $\mathrm{Br}$ atoms.

As for $\Delta \mathrm{H}_{298}^{0}$, the attack of three halogen atoms to FCHO, the $\Delta E \mathrm{~s}$ and $\Delta \mathrm{H}_{298}^{0} \mathrm{~s}$ were increased when the halogen atoms changed from $\mathrm{F}$ to $\mathrm{Cl}$ to $\mathrm{Br}$ atoms. This finding suggested that halogenated formaldehydes could be more easily abstracted by $\mathrm{F}$ atoms than $\mathrm{Cl}$ or $\mathrm{Br}$ atoms. Similar feature can be found from the reaction of three halogen atoms and $\mathrm{ClCHO}$ and $\mathrm{BrCHO}$. On the other hand, for $\mathrm{F}$ $\mathrm{R}_{\mathrm{abs}-\mathrm{Cl}}$ and $\mathrm{Cl}-\mathrm{R}_{\mathrm{abs}-\mathrm{Cl}}$ channels (Fig. $\mathrm{S} 1$ ), there is a complex on the reactants and products side, respectively, denoted as $\mathrm{CR}$ and $\mathrm{CP}$, in which the relative energies were -0.47 $\left(\mathrm{F}-\mathrm{CR}_{\mathrm{abs}-\mathrm{Cl}}\right),-43.94\left(\mathrm{~F}-\mathrm{CP}_{\mathrm{abs}-\mathrm{Cl}}\right),-2.41\left(\mathrm{Cl}-\mathrm{CR}_{\mathrm{abs}-\mathrm{Cl}}\right)$, and $-11.05\left(\mathrm{Cl}-\mathrm{CP}_{\mathrm{abs}-\mathrm{Cl}}\right) \mathrm{kcal} \mathrm{mol}^{-1}$ below the corresponding reactants, respectively (Table S3). Also, there exist two Cl$\mathrm{CR}_{\mathrm{abs}-\mathrm{F}}$ and $\mathrm{Br}-\mathrm{CR}_{\mathrm{abs}-\mathrm{F}}$ complexes located at the entrance of Cl-CR $\mathrm{Cbs}_{\mathrm{ab}-\mathrm{F}}$ and $\mathrm{Br}-\mathrm{CR}_{\mathrm{abs}-\mathrm{F}}$ channels, and the stabilization energies are all lower than the corresponding reactants by about $0.7 \mathrm{kcal} \mathrm{mol}^{-1}$.

In addition, the standard formation enthalpy $\left(\Delta \mathrm{H}_{f, 298}^{0}\right)$ of species is necessary to determine the kinetics of reaction process and the thermodynamic properties. Hence, the isodesmic reaction method (IUPAC) was performed to obtain the $\Delta \mathrm{H}_{f, 298}^{0}$ of main species without the experimental values, such as $\mathrm{ClCHO}, \mathrm{BrCHO}$, and the corresponding radicals, and presented in Table S4. The method was used in 
this study as a hypothetical reaction, in which the chemical bond broken model in the reactants is the same as the formed model in the products. Therefore, the following isodesmic reactions were chosen due to the simple configuration of $\mathrm{CH}_{4}$ (Ji et al., 2007):

$$
\begin{array}{cc}
\mathrm{QCHO}+\mathrm{CH}_{4} \rightarrow \mathrm{HCHO}+\mathrm{CH}_{3} \mathrm{Q}(\mathrm{Q}=\mathrm{F}, \mathrm{Cl}, \mathrm{Br}) & (\mathrm{R} 1-\mathrm{R} 3) \\
\mathrm{QCO}+\mathrm{CH}_{4} \rightarrow \mathrm{HCO}+\mathrm{CH}_{3} \mathrm{Q}(\mathrm{Q}=\mathrm{F}, \mathrm{Cl}, \mathrm{Br}) . & (\mathrm{R} 4-\mathrm{R} 6)
\end{array}
$$

The derivation procedure was as follows: (1) the SPE was calculated at the QCISD(T)/6-311+G(2df,2p) level using the geometries obtained by the PMP $2 / 6-311+\mathrm{G}(\mathrm{d}, \mathrm{p})$ level for all products and reactants involved in R1-3 and R4-6; (2) the heat corrections were used to obtain the $\Delta \mathrm{H}_{298}^{0}$ of Reaction (R1)-(R3) and Reaction (R4)-(R6) at $298 \mathrm{~K}$ using standard statistical thermodynamic methods; (3) the aforementioned reaction enthalpies were combined with the known experimental data in Reaction (R1)-(R3) and Reaction (R4)-(R6) (HCHO $-27.69 \mathrm{kcal} \mathrm{mol}^{-1}$; $\mathrm{HCO}-10.39 \mathrm{kcal} \mathrm{mol}^{-1} ; \quad \mathrm{CH}_{3} \mathrm{Cl}, \quad-19.99 \mathrm{kcal} \mathrm{mol}^{-1}$; $\mathrm{CH}_{3} \mathrm{~F}, \quad-55.97 \mathrm{kcal} \mathrm{mol}^{-1} ; \quad \mathrm{CH}_{3} \mathrm{Br}, \quad-9.08 \mathrm{kcal} \mathrm{mol}^{-1}$; $\mathrm{CH}_{4},-17.89 \mathrm{kcal} \mathrm{mol}^{-1}$ ) (NIST) to calculate the required $\Delta \mathrm{H}_{f, 298}^{0}$. As shown in Table $\mathrm{S} 4$, the calculated $\Delta \mathrm{H}_{f, 298}^{0}$ were $-46.2,-32.8,-5.1$, and $3.4 \mathrm{kcal} \mathrm{mol}^{-1}$ for $\mathrm{ClCHO}$, $\mathrm{BrCHO}, \mathrm{ClCO}$, and $\mathrm{BrCO}$, respectively. Despite the lack of experimental data that prevents full comparison between the theoretical data and the experimental $\Delta \mathrm{H}_{f, 298}^{0}$, the calculated $\Delta \mathrm{H}_{f, 298}^{0}$ of FCHO $\left(-92.6 \mathrm{kcal} \mathrm{mol}^{-1}\right)$ and FCO $\left(-41.5 \mathrm{kcal} \mathrm{mol}^{-1}\right)$ were in line with the available experimental values $\left(-89.96 \mathrm{kcal} \mathrm{mol}^{-1}\right.$ and $-41.95 \mathrm{kcal} \mathrm{mol}^{-1}$ for FCHO and FCO, respectively) in the reference (NIST). These results indicated that the QCISD(T)//PMP2 level can effectively model the $\Delta \mathrm{H}_{f, 298}^{0}$ of these species. Thus, it is expected that the calculated $\Delta \mathrm{H}_{f, 298}^{0}$ can provide reliable information for experimental investigations in the future.

\subsubsection{X-addition pathways}

For $\mathrm{Cl}$ or $\mathrm{Br}$ atoms addition to three halogenated formaldehydes, the $\Delta E$ s of these addition pathways were too high to overcome (Table 1), and these addition pathways were endothermic at least with $10 \mathrm{kcal} \mathrm{mol}^{-1}\left(\Delta \mathrm{H}_{298}^{0}\right)$. Thus, as indicated by the $\Delta E$ and $\Delta \mathrm{H}_{298}^{0}$, the addition pathways mentioned above were not likely to occur under the atmospheric conditions. Therefore, this section will mainly focus on the pathways of $\mathrm{F}$ atoms addition onto three halogenated formaldehydes (F-addition pathway).

For the F-addition pathways (Fig. S2), the formation of $\mathrm{C}-\mathrm{F}$ bond was always the same. Thus, the earliness of the TSs can be directly inferred from the forming C ...F distance. That is, the longer the $\mathrm{C} \cdots \mathrm{F}$ distance is, the earlier the TS is (Iuga et al., 2008). Figure S2 showed that the F-TS ${ }_{\text {add-Cl }}$ pathway was the earliest among three addition TSs, suggesting that this pathway was more exothermic than the F- $R_{\text {add-F }}$ and F- $R_{\text {add-Br }}$ pathways according to

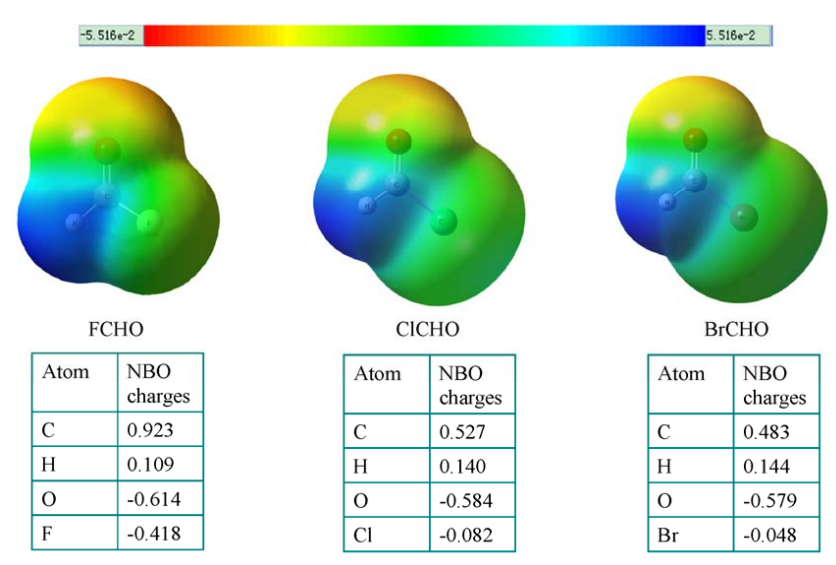

Fig. 1. Calculated molecular electrostatic potential and NBO charges (in e) for the reactants.

the Hammond postulate (Hammond, 1955). From Table 1, the order of $\Delta \mathrm{H}_{298}^{0} \mathrm{~s}$ were in line with that of the geometrical features of TS mentioned above, and the $\Delta \mathrm{H}_{298}^{0} \mathrm{~s}$ were $-23.62\left(\mathrm{~F}-\mathrm{R}_{\mathrm{add}-\mathrm{F}}\right),-24.32\left(\mathrm{~F}-\mathrm{R}_{\mathrm{add}-\mathrm{Cl}}\right)$, and -21.74 $\left(\mathrm{F}-\mathrm{R}_{\mathrm{add}-\mathrm{Br}}\right) \mathrm{kcal} \mathrm{mol}^{-1}$, respectively. The $\Delta E \mathrm{~s}$ of $\mathrm{F}-\mathrm{R}_{\mathrm{add}-\mathrm{X}}$ pathways were $5.70,7.38$, and $7.60 \mathrm{kcal} \mathrm{mol}^{-1}$ (Table 1), respectively, with the increasing order of $\Delta E\left(\mathrm{~F}-\mathrm{R}_{\text {add-F }}\right)$ $<\Delta E\left(\mathrm{~F}-\mathrm{R}_{\text {add-Cl }}\right)<\Delta \mathrm{E}\left(\mathrm{F}-\mathrm{R}_{\text {add-Br }}\right)$. This result indicated that the addition pathways of $\mathrm{F}$ atom onto three halogenated formaldehydes would become increasingly more difficult as the electronegativity of halogen atoms was decreased in halogenated formaldehydes.

\subsubsection{Natural bond orbital (NBO) calculation analysis}

To further understand the nature of the title atmospheric reaction mechanisms, the distribution of molecular electrostatic potential as well as NBO charges were carried out at the QCISD(T)/6-311+G(2df,2p) level. The results were illustrated in Fig. 1. The most positive and negative potential were assigned to be blue and red, respectively. The more positive potential bond (bluer) is preferred to the nucleophiles attack. Therefore, the blue color of $\mathrm{H}$ atoms was deeper than that of $\mathrm{C}$ atoms in three halogenated formaldehydes (Fig. 1). That is, the $\mathrm{H}$ atoms appeared to have stronger positive potential bond than the $\mathrm{C}$ atoms. This finding suggested that the $\mathrm{H}$-abstraction pathways were expected to more likely occur than the corresponding $\mathrm{X}$-addition pathways. The NBO charges estimated for $\mathrm{H}$ atoms were 0.109 , 0.104 , and $0.144 \mathrm{e}$, respectively, indicating an increased trend from $\mathrm{FCHO}$ to $\mathrm{ClCHO}$ to $\mathrm{BrCHO}$. Therefore, the $\mathrm{H}$ atoms in three molecules were more and more easy to be abstracted by halogen atoms and could be explained in terms of the inductive effect of halogen substitution. For three halogenated formaldehydes, the inductive effect gradually weakens from the electron group $-\mathrm{F}$ to $-\mathrm{Cl}$ to $-\mathrm{Br}$, and thus the electrons on the $\mathrm{C}$ atom of carbonyl group were harder and harder 
to be attracted, thereby increasing the electron density of $\mathrm{H}$ atom. As expected, the reactivity of the $\mathrm{H}$-abstraction pathway should be increased from $\mathrm{FCHO}$ to $\mathrm{ClCHO}$ and then to $\mathrm{BrCHO}$.

\subsection{Reaction kinetics}

The theoretical predictions herein can help us to develop reliable models for the real atmospheric reactions occurring within the temperature range from the earth surface to tropopause (200-368 K). Therefore, in this section, the DLD calculations were performed with the CVT plus interpolated single-point energies method (Chuang et al., 1999) using the QCISD(T)//PMP2 level to compute the rate constants at every $10 \mathrm{~K}$ as well as the temperature point with the experimental values. For the convenience of the following discussion, the calculated rate constants using CVT plus SCT were denoted as CVT/SCT rate constants. The obtained rate constants and the available experimental data were compared in Fig. S3. The temperature dependences of branching ratios between the $\mathrm{H}$-abstraction and the $\mathrm{X}$-addition pathways were also exhibited in Fig. S4. Tables S5 to S7 list the rate constants of each pathway and the total rate constants.

The CVT/SCT rate constants of the F- $\mathrm{R}_{\text {abs-F }}$ pathway (Fig. S3a) were in good agreement with most experimental data (Behr et al., 1993, 1998; Francisco et al., 1990; Hasson et al., 1998; Meagher et al., 1997). For example, the calculated rate constant of $8.1 \times 10^{-13} \mathrm{~cm}^{3}$ molecule $\mathrm{s}^{-1} \mathrm{~s}^{-1}$ at $298 \mathrm{~K}$ perfectly matched with the experimental values of $(8.8 \pm 1.4) \times 10^{-13} \mathrm{~cm}^{3}$ molecule $\mathrm{c}^{-1} \mathrm{~s}^{-1}$ (Behr et al., 1993) and $(8.0 \pm 1.0) \times 10^{-13} \mathrm{~cm}^{3}$ molecule ${ }^{-1} \mathrm{~s}^{-1}$ (Hasson et al., 1998), but was slightly lower than that of $2.11 \times 10^{-12} \mathrm{~cm}^{3}$ molecule ${ }^{-1} \mathrm{~s}^{-1}$ (Francisco et al., 1990). With respect to $\mathrm{Cl}-\mathrm{R}_{\mathrm{abs}-\mathrm{F}}$ pathway (Fig. S3b), the rate constants matched with the available experimental data (Bednarek et al., 1996; Edney et al., 1992; Meagher et al., 1997; Wallington et al., 1992) in the temperature range of $244-298 \mathrm{~K}$ due to the largest deviation within a factor of 1.5. For instance, the calculated rate constant of $1.7 \times 10^{-15} \mathrm{~cm}^{3}$ molecule ${ }^{-1} \mathrm{~s}^{-1}$ at $295 \mathrm{~K}$ agreed well with the experimental values of $(1.9 \pm 0.2) \times 10^{-15}$ (Meagher et al., 1997) and $(2.1 \pm 0.2) \times 10^{-15} \mathrm{~cm}^{3}$ molecule ${ }^{-1} \mathrm{~s}^{-1}$ (Edney et al., 1992). For Cl-R $\mathrm{R}_{\mathrm{abs}-\mathrm{Cl}}$ pathway (Fig. S3c), the calculated rate constant was slightly lower than the data achieved by Sanhueza et al. (1975) at $305 \mathrm{~K}$, but were well accorded with other experimental data (Catoire et al., 1996; Libuda et al., 1990; Orlando, 1999; Wallington et al., 1996). Fitted by the CVT/SCT rate constants, the Arrhenius expression was obtained to be $1.70 \times 10^{-11} \exp (-940 \mathrm{~K} / T) \mathrm{cm}^{3}$ molecule ${ }^{-1} \mathrm{~s}^{-1}$, which was in agreement with the experimental expressions of $\left.1.39 \times 10^{-11} \exp ((-866 \pm 168) \mathrm{K} / T)\right) \mathrm{cm}^{3}$ molecule $^{-1} \mathrm{~s}^{-1}$ within the temperature range $266-322 \mathrm{~K}$ (Libuda et al., 1990). On the basis of the previous discussion, the theoretical results matched well with the available experimental data
Table 2. Total Rate Constants of the X + QCHO Reactions at $298 \mathrm{~K}$ (in $\mathrm{cm}^{3}$ molecule $\mathrm{e}^{-1} \mathrm{~s}^{-1}$ ).

\begin{tabular}{llll}
\hline $\mathrm{X}$ & $\mathrm{F}$ & $\mathrm{Cl}$ & $\mathrm{Br}$ \\
\hline QCHO & & & \\
\hline FCHO & $8.08 \times 10^{-13}$ & $1.95 \times 10^{-15}$ & $1.27 \times 10^{-21}$ \\
ClCHO & $4.23 \times 10^{-12}$ & $7.25 \times 10^{-12}$ & $1.79 \times 10^{-15}$ \\
BrCHO & $8.28 \times 10^{-12}$ & $1.31 \times 10^{-12}$ & $1.10 \times 10^{-15}$ \\
HCHO $^{*}$ & $4.5 \times 10^{-11}$ & $8.0 \times 10^{-11}$ & $1.8 \times 10^{-12}$ \\
\hline
\end{tabular}

* From the experimental data; Beukes et al. (2000).

owing to the largest deviation factor of 1.6. Thus, the rate constants obtained at the QCISD(T)//PMP2 levels were reliable within the atmospheric temperature range from 200 to $368 \mathrm{~K}$, which is particularly important for the atmospheric reactions without experimental data.

The total rate constants of same halogen atom reaction with different halogenated formaldehydes within the temperature range of $200-368 \mathrm{~K}$ were demonstrated in Fig. 2a-c. These rate constants at $298 \mathrm{~K}$ were also presented in Table 2. For the reactions of $\mathrm{F}$ atom with different halogenated formaldehydes (Table 2), the total rate constants obtained were $8.08 \times 10^{-13}(\mathrm{~F}+\mathrm{FCHO}), 4.23 \times 10^{-12}(\mathrm{~F}+\mathrm{ClCHO})$, and $8.28 \times 10^{-12} \quad(\mathrm{~F}+\mathrm{BrCHO}) \mathrm{cm}^{3}$ molecule $\mathrm{e}^{-1} \mathrm{~s}^{-1}$ at $298 \mathrm{~K}$. The rate constants increased in the order of $k(\mathrm{~F}+\mathrm{FCHO})<k(\mathrm{~F}+\mathrm{ClCHO})<k(\mathrm{~F}+\mathrm{BrCHO})$, which was consistent with the analysis values of potential barrier and NBO calculation. In addition, from Fig. 2a, it can be found that as the temperature rises, the rate constants increase, implying that increasing temperature will be benefit from the reaction of $\mathrm{F}$ atom with different halogenated formaldehydes. The similar results can be drawn from the reactions of different halogenated formaldehydes with $\mathrm{Cl}$ or $\mathrm{Br}$ atoms. For the same halogenated formaldehyde reactions with different halogen atoms, the total CVT/SCT results were also summarized in Fig. 2d-f. For the reactions of ClCHO with different halogen atoms (Fig. 2d), the theoretical results decreased in the order of $k(\mathrm{~F}+\mathrm{ClCHO})>k(\mathrm{Cl}+\mathrm{ClCHO})$ $>k(\mathrm{Br}+\mathrm{ClCHO})$. The similar trend can also be observed for the reactions of $\mathrm{FCHO}$ and $\mathrm{BrCHO}$ with different halogen atoms. The kinetics results showed that the reactions of $\mathrm{F}$ atoms with halogenated formaldehydes were faster than those with $\mathrm{Cl}$ and $\mathrm{Br}$ atoms, but due to abundant $\mathrm{Cl}$ and $\mathrm{Br}$ atoms in the MBL, the halogenated formaldehydes reacted with $\mathrm{Cl}$ and $\mathrm{Br}$ atoms were still important even more than those with $\mathrm{F}$ atoms under the MBL. To confirm the contributions of halogen atoms in halogenated formaldehydes, the rate constants of parent formaldehyde reaction with halogen atoms reported by Beukes et al. (2000) were also presented in Table 2. The rate constants of formaldehydes with halogen atoms were larger than those of halogenated formaldehydes with the corresponding halogen atoms. This result indicated that the decrease in the atmospheric activities of three 


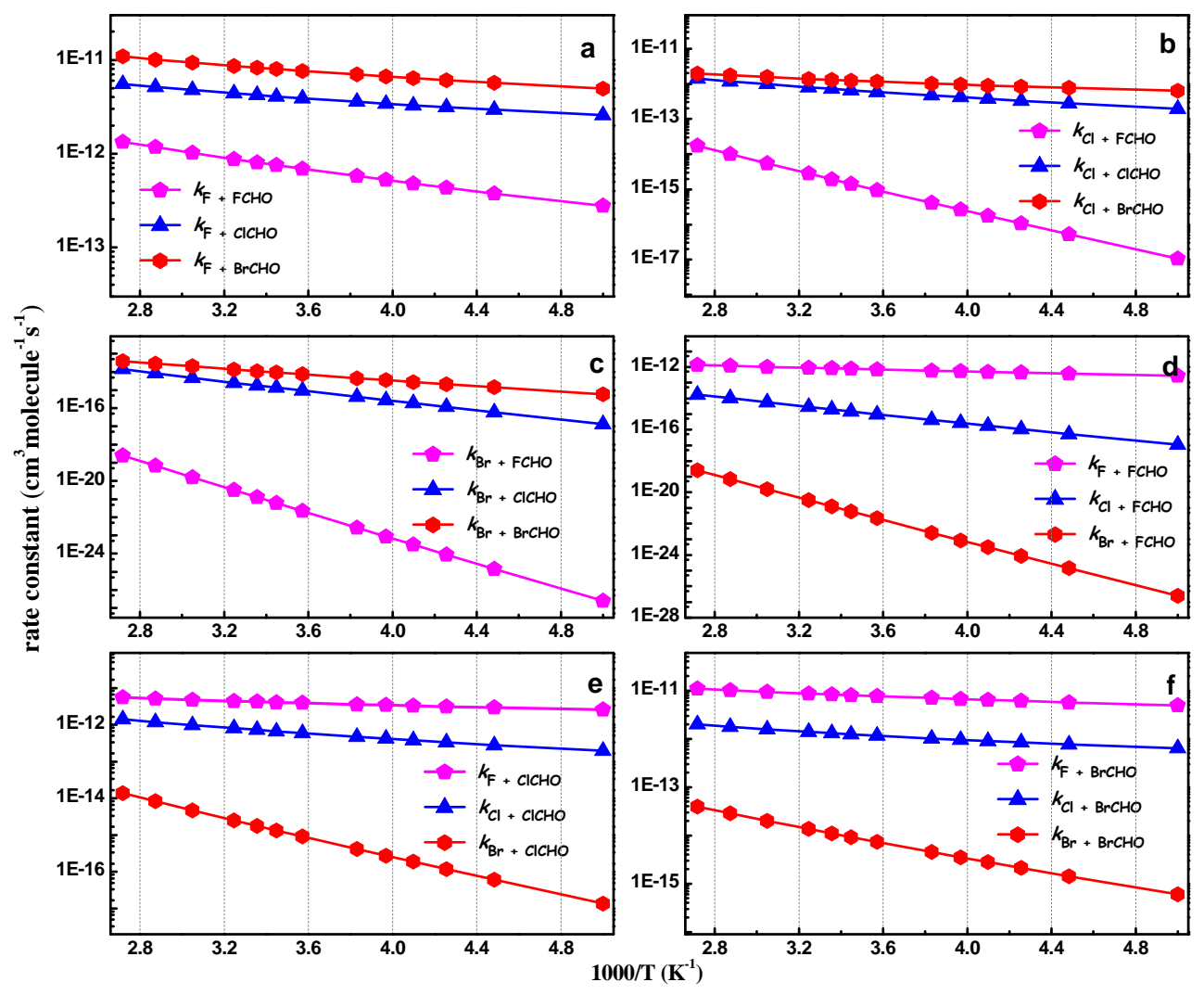

Fig. 2. Plot of the CVT/SCT rate constants versus 1000/T within the temperature range of 200-368 K for the reactions of (a) $\mathrm{F}+\mathrm{QCHO}$, (b) $\mathrm{Cl}+\mathrm{QCHO}$, (c) $\mathrm{Br}+\mathrm{QCHO}$, (d) $\mathrm{X}+\mathrm{FCHO}$, (e) $\mathrm{X}+\mathrm{ClCHO}$, and (f) $\mathrm{X}+\mathrm{BrCHO}$. Herewith, $\mathrm{X}$ and $\mathrm{Q}$ are $\mathrm{F}, \mathrm{Cl}, \mathrm{Br}$ atoms.

halogenated formaldehydes with halogen atom substitution compared with their parent formaldehydes.

Figure S4 showed that for all nine atmospheric reactions, the contribution of all $\mathrm{X}$-addition pathways to the total rate constant was almost equal to zero. Such finding suggested that the addition-elimination pathways were negligible within the temperature range of 200-368 K. Therefore, the halogenated formyl radical ( $\mathrm{QCO}$, where $\mathrm{Q}=\mathrm{F}, \mathrm{Cl}, \mathrm{Br}$ ) and hydrogen halide $(\mathrm{HX}$, where $\mathrm{X}=\mathrm{F}, \mathrm{Cl}, \mathrm{Br}$ ) were the dominant products, and the addition intermediates (such as $\mathrm{HC}(\mathrm{O}) \mathrm{F}_{2}, \mathrm{HC}(\mathrm{O}) \mathrm{ClF}$, etc.) were difficult to form at temperature range from 200 to $368 \mathrm{~K}$.

To predict the rate constants of the title reactions in the temperatures without experimental data, the relationship was attempted between the temperature and the rate constants. Within the atmospheric temperature ranges of 200-368 K, the modified Arrhenius formulas were listed in Tables 3 and S8. The pre-exponential factor, the rate constants, and the activation energy can be drawn from these formulas.

\subsubsection{The fate of main atmospheric intermediates}

To better ascertain the environmental impact of the title atmospheric reactions, $\mathrm{ClCO}$ and $\mathrm{HC}(\mathrm{O}) \mathrm{ClF}$ were used as examples of the reaction intermediates of the $\mathrm{H}$-abstraction and
Table 3. The modified Arrhenius formulas for $k=A T^{\mathrm{B}} \exp (-\mathrm{C} / T)$ within the temperature range of 200-368 K.

\begin{tabular}{lllr}
\hline Reaction & $\mathrm{A}^{\mathrm{a}}$ & $\mathrm{B}$ & $\mathrm{C}^{\mathrm{b}}$ \\
\hline $\mathrm{FCHO}+\mathrm{F} \rightarrow$ products & $1.74 \times 10^{-16}$ & 1.63 & 256 \\
$\mathrm{ClCHO}+\mathrm{F} \rightarrow$ products & $1.17 \times 10^{-15}$ & 1.41 & -40 \\
$\mathrm{BrCHO}+\mathrm{F} \rightarrow$ products & $4.60 \times 10^{-15}$ & 1.31 & -6 \\
$\mathrm{FCHO}+\mathrm{Cl} \rightarrow$ products & $1.55 \times 10^{-19}$ & 3.08 & 2415 \\
$\mathrm{ClCHO}+\mathrm{Cl} \rightarrow$ products & $1.97 \times 10^{-19}$ & 2.74 & 140 \\
$\mathrm{BrCHO}+\mathrm{Cl} \rightarrow$ products & $3.70 \times 10^{-19}$ & 2.54 & -182 \\
$\mathrm{FCHO}+\mathrm{Br} \rightarrow$ products & $1.09 \times 10^{-19}$ & 3.44 & 7165 \\
$\mathrm{ClCHO}+\mathrm{Br} \rightarrow$ products & $7.94 \times 10^{-19}$ & 2.72 & 2309 \\
$\mathrm{BrCHO}+\mathrm{Br} \rightarrow$ products & $8.33 \times 10^{-20}$ & 2.73 & 1113 \\
\hline
\end{tabular}

${ }^{\text {a }}$ Units in $\mathrm{cm}^{3}$ molecule ${ }^{-1} \mathrm{~s}^{-1}$.

${ }^{\mathrm{b}} C=\frac{E}{R}, E=E_{\mathrm{a}}-n R T$, in which $C$ (in $\mathrm{K}$ ), $E$ (in kcal $\mathrm{mol}^{-1}$ ) and $n$ are the fitting parameters, and $E_{\mathrm{a}}$ (in kcal mol${ }^{-1}$ ) and $R$ (in $\mathrm{kcal} \mathrm{mol}^{-1} \cdot \mathrm{K}$ ) are the activation energy and the gas constant, respectively (Zheng et al., 2010).

$\mathrm{X}$-addition channels, respectively, in the presence of $\mathrm{O}_{2}$ and halogen atoms. The four possible atmospheric degradation pathways of $\mathrm{ClCO}$ radical were presented in Fig. 3, in which the reactions of $\mathrm{ClCO}$ with $\mathrm{Cl}$ atom (pathways 2 and 3 ) and oxygen atom (pathways 4 ) corresponds to the elimination of 


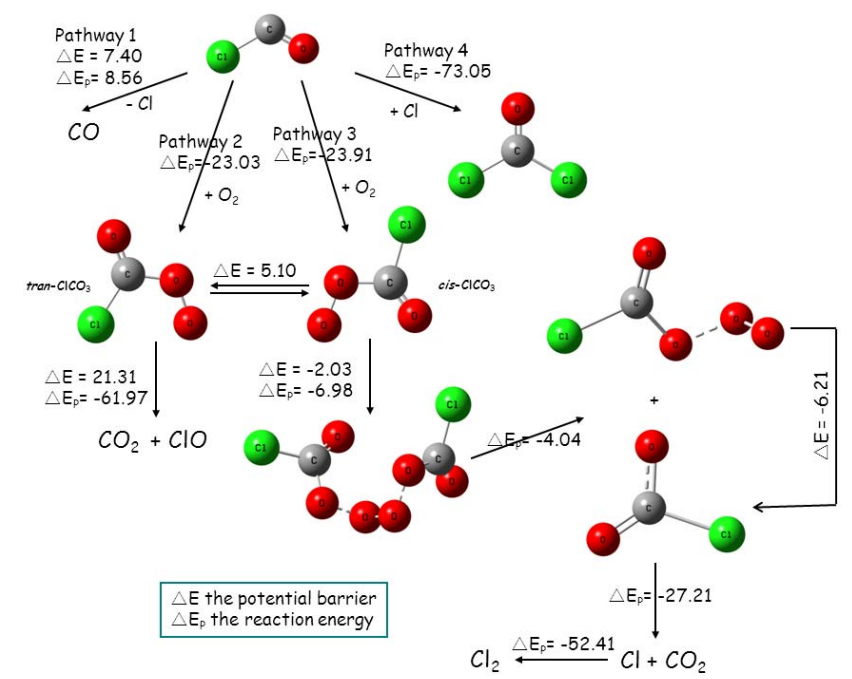

Fig. 3. Possible atmospheric degradation pathways of $\mathrm{ClCO}$ radical at the QCISD(T)/6-311+G(2df,2p)//PMP2/6-311+G(d,p) level (in $\mathrm{kcal} \mathrm{mol}^{-1}$ ).

$\mathrm{Cl}$ atom from $\mathrm{ClCO}$ (pathways 1). As shown in Fig. 3, pathway 1 had difficulty occurring because of higher potential barrier height than those of other pathways, whereas pathways 2-4 were all barrier-free processes. To further confirm these barrier-free processes, the point-wise potential curve was performed and the results were shown in Figs. S5-S7 (the detailed discussion is presented in Supplementary Material). Pathways 2 and 3 were exothermic processes with the exothermic energies of -23.03 and $-23.91 \mathrm{kcal} \mathrm{mol}^{-1}$ to form two isomers cis- $\mathrm{ClCO}_{3}$ and trans- $\mathrm{ClCO}_{3}$ with high activity, in which could be easily transformed to each other with a small internal rotation barrier $\left(5.10 \mathrm{kcal} \mathrm{mol}^{-1}\right)$. Furthermore, both species can be easily degraded. For trans- $\mathrm{ClCO}_{3}$, the most feasible pathway was to undergo a concerted O-shift and $\mathrm{C}-\mathrm{Cl}$ bond cleavage, leading to the final products $\left(\mathrm{CO}_{2}\right.$ and $\mathrm{ClO}$ ), in which the potential barrier height and reaction energy $\left(\Delta E_{\mathrm{p}}\right)$ was 21.31 and $-61.97 \mathrm{kcal} \mathrm{mol}^{-1}$. In the absence of other radicals, two cis- $\mathrm{ClCO}_{3}$ could easily combine each other to produce $\mathrm{CCl}(\mathrm{O}) \mathrm{OOCCl}(\mathrm{O})$ owing to the low potential barrier heights with $-2.03 \mathrm{kcal} \mathrm{mol}^{-1}$ and strongly exothermic energy with $-6.98 \mathrm{kcal} \mathrm{mol}^{-1}$. This intermediate $\mathrm{CCl}(\mathrm{O}) \mathrm{OOCCl}(\mathrm{O})$ could dissociated directly to give products $\mathrm{ClCO}_{2}$ and $\mathrm{Cl}(\mathrm{O}) \mathrm{CO}_{3}\left(\Delta E_{\mathrm{p}}=-4.04 \mathrm{kcal} \mathrm{mol}^{-1}\right)$. The $\mathrm{Cl}(\mathrm{O}) \mathrm{CO}_{3}$ could further dissociated to produce $\mathrm{ClCO}_{2}$ and $\mathrm{O}_{2}\left(\Delta E=-6.21 \mathrm{kcal} \mathrm{mol}^{-1}\right)$, and finally, due to high exothermic energy $\left(-27.21 \mathrm{kcal} \mathrm{mol}^{-1}\right)$, the $\mathrm{ClCO}_{2}$ could be decomposed to produce $\mathrm{CO}_{2}$ and $\mathrm{Cl}_{2}$. As for pathway 4 , the $\mathrm{ClCO}$ radical could be prefer to react with $\mathrm{Cl}$ atom to form phosgene by a strongly exothermic process with an energy decrease of $-73.05 \mathrm{kcal} \mathrm{mol}^{-1}$. Phosgene is well known to be slightly soluble in liquid water, in which it may yield $\mathrm{CO}_{2}$ and $\mathrm{HCl}$ as final gaseous products (Hatakeyama et al., 1989). Based on the aforementioned results, the $\mathrm{ClCO}$ radical could primarily react with $\mathrm{Cl}$ atoms to produce phosgene where there is abundant $\mathrm{Cl}$ atoms in the atmosphere. Otherwise, the $\mathrm{ClCO}$ radical could be transformed into $\mathrm{CO}_{2}, \mathrm{Cl}_{2}$, and $\mathrm{ClO}$ in the presence of $\mathrm{O}_{2}$.

For the addition intermediate $\mathrm{HC}(\mathrm{O}) \mathrm{ClF}$, there maybe exist three degradation pathways: H-elimination, Clelimination, and HF-elimination pathways (Scheme S1, as denoted F-R $\mathrm{R}_{\text {elm-Cl }} 1$, F-R $\mathrm{R}_{\text {elm-Cl }} 2$, and F-R $\mathrm{R}_{\text {elm-Cl }} 3$ ). Table S9 listed the energies at different pathways, in which the energy of the corresponding intermediate was set to zero as reference. As shown in table, the $\Delta E$ of $\mathrm{F}-\mathrm{R}_{\mathrm{elm}-\mathrm{Cl}} 2$ pathway was much lower at least $10 \mathrm{kcal} \mathrm{mol}^{-1}$ than those of F$\mathrm{R}_{\mathrm{elm}-\mathrm{Cl}} 1$ and $\mathrm{F}-\mathrm{R}_{\mathrm{elm}-\mathrm{Cl}} 3$ pathways. This result suggested that F- $\mathrm{R}_{\text {elm-Cl}} 2$ pathway could easily occur from the viewpoint of kinetics to release $\mathrm{Cl}$ atoms. However, the exothermic energy of the F-R $\mathrm{R}_{\mathrm{elm}-\mathrm{Cl}} 3$ pathway $\left(-19.73 \mathrm{kcal} \mathrm{mol}^{-1}\right)$ was lower $\left(6 \mathrm{kcal} \mathrm{mol}^{-1}\right)$ than that of the F-Relm-Cl 2 pathway. This indicated that the formation of $\mathrm{HF}$ and $\mathrm{ClCO}$ was thermodynamically favorable. Anyway, the addition pathways were difficult to occur, thus these products were not obtained under the atmospheric conditions.

\section{Environmental implications}

To evaluate the specific atmospheric region where the reactions of the halogenated formaldehydes with halogen atoms occur, the rate constants at different altitudes were also calculated (Table 4). From table, the rate constants decreased with increasing the altitudes, and the decrease in the halogen atom reaction with FCHO was faster than those of halogen atoms with other halogenated formaldehydes. For example, the rate constants at sea level were $4.8(\mathrm{~F}+\mathrm{FCHO}), 2.2$ $(\mathrm{F}+\mathrm{ClCHO})$, and $2.0(\mathrm{~F}+\mathrm{BrCHO})$ times larger than those at $12 \mathrm{~km}$ height above sea level. As the results displayed in Table 4 and Fig. S4, the QCO and HX were always found as dominated intermediates within the altitude between 0 and $12 \mathrm{~km}$, but the products of addition pathways were difficult to produce. Particularly at sea level, the reaction intermediates of QCO and HX were obtained almost exclusively with the ratio of $100 \%$. According to previously mentioned results, the intermediate, QCO, was willing to react with halogen atoms to form unstable compounds in specific areas where there are abundant halogen atoms in the atmosphere (for example, MBL). These compounds were slightly soluble and then yield $\mathrm{CO}_{2}$ and $\mathrm{HX}$ as final gaseous products. Otherwise, the QCO were degraded to form $\mathrm{CO}_{2}, \mathrm{X}_{2}$, and $\mathrm{XO}$ in the presence of $\mathrm{O}_{2}$ and halogen atoms. In particular, for the reaction of $\mathrm{ClCHO}$ with $\mathrm{Cl}$ atoms, the phosgene and $\mathrm{ClO}$ were found during the atmospheric degradation process. Phosgene is well known as a highly toxic colourless gas (Fu et al., 2007) that can endanger human health via inhalation and exposure (Stanek et al., 2011), and $\mathrm{ClO}$ is also a key ozone destruction catalyst (Solomon, 1999). Therefore, halogenated formaldehydes as intermediates of the atmospheric 
Table 4. Calculated CVT/SCT rate constants of $\mathrm{H}$-abstraction and $\mathrm{X}$-addition pathways at different heights* in the earth atmosphere (in $\mathrm{cm}^{3}$ molecule $\mathrm{s}^{-1}$ ).

\begin{tabular}{|c|c|c|c|c|c|c|c|}
\hline \multirow[t]{2}{*}{$h(\mathrm{~km})$} & \multirow[t]{2}{*}{$T(\mathrm{~K})$} & \multicolumn{2}{|c|}{$\mathrm{F}+\mathrm{FCHO} \rightarrow$ products } & \multicolumn{2}{|c|}{$\mathrm{F}+\mathrm{ClCHO} \rightarrow$ products } & \multicolumn{2}{|c|}{$\mathrm{F}+\mathrm{BrCHO} \rightarrow$ products } \\
\hline & & $k_{\mathrm{abs}}$ & $k_{\text {add }}$ & $k_{\mathrm{abs}}$ & $k_{\text {add }}$ & $k_{\mathrm{abs}}$ & $k_{\text {add }}$ \\
\hline 0 & 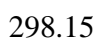 & $09 \times 10^{-}$ & $1.01 \times 10^{-16}$ & $4.23 \times 10^{-12}$ & $1.75 \times 10^{-}$ & $5.49 \times 10^{-12}$ & $1.19 \times 10^{-19}$ \\
\hline 0 & 0.19 & $7.43 \times 10^{-13}$ & $6.72 \times 10^{-17}$ & $4.05 \times 10^{-12}$ & $1.22 \times 10^{-16}$ & $5.46 \times 10^{-12}$ & $7.83 \times 10^{-20}$ \\
\hline 2 & 75.21 & $6.61 \times 10^{-13}$ & $3.78 \times 10^{-17}$ & $3.82 \times 10^{-12}$ & $7.30 \times 10^{-17}$ & $5.42 \times 10^{-12}$ & $4.67 \times 10^{-20}$ \\
\hline 4 & 2.23 & $5.83 \times 10^{-13}$ & $2.02 \times 10^{-17}$ & $3.59 \times 10^{-12}$ & $4.21 \times 10^{-17}$ & $5.32 \times 10^{-12}$ & $2.94 \times 10^{-20}$ \\
\hline 6 & 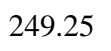 & $5.10 \times 10^{-13}$ & $1.02 \times 10^{-17}$ & $3.37 \times 10^{-12}$ & $2.31 \times 10^{-17}$ & $5.29 \times 10^{-12}$ & $1.98 \times 10^{-20}$ \\
\hline 8 & 6.27 & $4.41 \times 10^{-13}$ & $4.87 \times 10^{-18}$ & $3.15 \times 10^{-12}$ & $1.20 \times 10^{-17}$ & $5.28 \times 10^{-12}$ & $1.43 \times 10^{-20}$ \\
\hline 10 & 3.29 & $3.78 \times 10^{-13}$ & $2.16 \times 10^{-18}$ & $2.94 \times 10^{-12}$ & $5.95 \times 10^{-18}$ & $5.30 \times 10^{-12}$ & $1.08 \times 10^{-20}$ \\
\hline 12 & 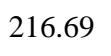 & $3.48 \times 10^{-13}$ & $1.39 \times 10^{-18}$ & $2.83 \times 10^{-12}$ & $4.06 \times 10^{-18}$ & $5.32 \times 10^{-12}$ & $9.55 \times 10^{-21}$ \\
\hline \multirow[t]{2}{*}{$h(\mathrm{~km})$} & & \multicolumn{2}{|c|}{$\mathrm{Cl}+\mathrm{FCHO} \rightarrow$ products } & \multicolumn{2}{|c|}{$\mathrm{Cl}+\mathrm{ClCHO} \rightarrow$ products } & \multicolumn{2}{|c|}{$\mathrm{Cl}+\mathrm{BrCHO} \rightarrow$ products } \\
\hline & & $k_{\mathrm{abs}}$ & $k_{\text {add }}$ & $k_{\mathrm{abs}}$ & $k_{\text {add }}$ & $k_{\mathrm{abs}}$ & $k_{\text {add }}$ \\
\hline 0 & & & & & & & \\
\hline 0 & 0.1 & & $3.74 \times 10^{-25}$ & $6.51 \times 10^{-13}$ & $6.80 \times 10^{-32}$ & $1.22 \times 10^{-12}$ & $1.13 \times 10^{-23}$ \\
\hline 2 & 275.21 & & & & $1.41 \times 10^{-32}$ & $1.12 \times 10^{-12}$ & $3.48 \times 10^{-24}$ \\
\hline 4 & 62.23 & $4.36 \times 10^{-16}$ & $2.92 \times 10^{-26}$ & $4.79 \times 10^{-13}$ & $2.53 \times 10^{-33}$ & $1.03 \times 10^{-12}$ & $9.61 \times 10^{-25}$ \\
\hline 6 & 1925 & $31 \times 1$ & $\times 10^{-27}$ & $4.05 \times 10^{-13}$ & $3.81 \times 10^{-}$ & $9.35 \times 10^{-13}$ & $2.34 \times 10^{-25}$ \\
\hline 8 & 6.27 & $1.15 \times 1$ & & $3.39 \times 10^{-13}$ & $4.68 \times 10^{-35}$ & $8.50 \times 10^{-13}$ & $4.90 \times 10^{-26}$ \\
\hline 10 & 23.29 & $5.33 \times 10^{-17}$ & $2.34 \times 10^{-28}$ & $2.81 \times 10^{-13}$ & $4.52 \times 10^{-36}$ & $7.71 \times 10^{-13}$ & $8.67 \times 10^{-27}$ \\
\hline 12 & 6.69 & $50 \times 10^{-17}$ & $8.85 \times 10^{-29}$ & $2.54 \times 10^{-13}$ & $1.24 \times 10^{-36}$ & $7.32 \times 10^{-13}$ & $3.33 \times 10^{-27}$ \\
\hline \multirow[t]{2}{*}{$h(\mathrm{~km})$} & & \multicolumn{2}{|c|}{$\mathrm{Br}+\mathrm{FCHO} \rightarrow$ products } & \multicolumn{2}{|c|}{$\mathrm{Br}+\mathrm{ClCHO} \rightarrow$ products } & \multicolumn{2}{|c|}{$\mathrm{Br}+\mathrm{BrCHO} \rightarrow$ products } \\
\hline & & $k_{\mathrm{abs}}$ & $k_{\text {add }}$ & $k_{\mathrm{abs}}$ & $k_{\text {add }}$ & $k_{\mathrm{abs}}$ & $k_{\text {add }}$ \\
\hline 0 & 8.15 & $8 \times 10^{-21}$ & $19 \times 10^{-31}$ & $80 \times 10^{-15}$ & $8.68 \times 10^{-31}$ & $1.11 \times 10^{-14}$ & $1.46 \times 10^{-28}$ \\
\hline 0 & 8.19 & $4.98 \times 10^{-22}$ & $2.19 \times 10^{-32}$ & $1.26 \times 10^{-15}$ & $1.88 \times 10^{-31}$ & $8.86 \times 10$ & $4.38 \times 10^{-29}$ \\
\hline 2 & 27521 & $1.31 \times 10^{-22}$ & $2.03 \times 10^{-33}$ & $7.60 \times 10^{-16}$ & $2.16 \times 10^{-32}$ & $6.51 \times 10^{-15}$ & $8.01 \times 10^{-30}$ \\
\hline 4 & 262.23 & $3.06 \times 10^{-23}$ & $1.49 \times 10^{-34}$ & $4.40 \times 10^{-16}$ & $2.02 \times 10^{-33}$ & $4.67 \times 10^{-15}$ & $1.24 \times 10^{-30}$ \\
\hline 6 & 249.25 & $6.18 \times 10^{-24}$ & $8.36 \times 10^{-36}$ & $2.43 \times 10^{-16}$ & $1.48 \times 10^{-34}$ & $3.26 \times 10^{-15}$ & $1.59 \times 10^{-31}$ \\
\hline 8 & 236.27 & $1.06 \times 10^{-24}$ & $3.44 \times 10^{-37}$ & $1.26 \times 10^{-16}$ & $8.13 \times 10^{-36}$ & $2.21 \times 10^{-15}$ & $1.63 \times 10^{-32}$ \\
\hline 10 & 223.29 & $1.50 \times 10^{-25}$ & $9.80 \times 10^{-39}$ & $6.13 \times 10^{-17}$ & $3.21 \times 10^{-37}$ & $1.44 \times 10^{-15}$ & $1.29 \times 10^{-33}$ \\
\hline 12 & 216.69 & $5.08 \times 10^{-26}$ & $1.37 \times 10^{-39}$ & $4.16 \times 10^{-17}$ & $5.37 \times 10^{-38}$ & $1.14 \times 10^{-15}$ & $3.18 \times 10^{-34}$ \\
\hline
\end{tabular}

* In the troposphere, the temperature drops about $6.49 \mathrm{~K}$ for every $1 \mathrm{~km}$ increase in altitude. Into the stratosphere (from $11 \mathrm{~km}$ height above the earth surface), the constant temperature is $216.69 \mathrm{~K}$ (Gonzalez et al., 2011).

degradation of VOCs, need ongoing comprehensive attention and further risk assessment in atmospheric environment.

\section{Supplementary material related to this article is available online at http://www.atmos-chem-phys.net/13/ 11277/2013/acp-13-11277-2013-supplement.pdf.}

Acknowledgements. This is contribution No. IS-1606 from GIGCAS. This work was financially supported by the Team Project from Natural Science Foundation of Guangdong Province, China (S2012030006604), the National Natural Science Foundation of China (41205088) and the Science and Technology Project of Guangdong Province, China (2011A030700003 and 2012A032300017). We also thank Professor Donald G. Truhlar for his providing POLYRATE program.
Edited by: R. Sander

\section{References}

Bednarek, G., Breil, M., Hoffmann, A., Kohlmann, J. P., Mors, V., and Zellner, R.: Rate and mechanism of the atmospheric degradation of 1,1,1,2-tetrafluoroethane (HFC-134a), Ber. Bunsen. Phys. Chem., 100, 528-539, 1996.

Behr, P., Goldbach, K., and Heydtmann, H.: The reaction of fuorine atoms with formyl fluoride and the CFO self-reaction at $293 \mathrm{~K}$, Int. J. Chem. Kinet., 25, 957-967, 1993.

Behr, P., Kaupert, C., Shafranovski, E., and Heydtmann, H.: Temperature dependence of the gas-phase reactions F + CHFO, $\mathrm{CFO}+\mathrm{F}$, and $\mathrm{CFO}+\mathrm{CFO}$, Int. J. Chem. Kinet., 30, 329-333, 1998. 
Beukes, J. A., D’Anna, B., Bakken, V., and Nielsen, C. J.: Experimental and theoretical study of the $\mathrm{F}, \mathrm{Cl}$ and $\mathrm{Br}$ reactions with formaldehyde and acetaldehyde, Phys. Chem. Chem. Phys., 2, 4049-4060, 2000.

Blotevogel, J., Borch, T., Desyaterik, Y., Mayeno, A. N., and Sale, T. C.: Quantum Chemical Prediction of Redox Reactivity and Degradation Pathways for Aqueous Phase Contaminants: An Example with HMPA, Environ. Sci. Technol., 44, 5868-5874, 2010.

Catoire, V., Lesclaux, R., Schneider, W. F., and Wallington, T. J.: Kinetics and mechanisms of the self-reactions of $\mathrm{CCl}_{3} \mathrm{O}_{2}$ and $\mathrm{CHCl}_{2} \mathrm{O}_{2}$ radicals and their reactions with $\mathrm{HO}_{2}$, J. Phys. Chem., 100, 14356-14371, 1996.

Chuang, Y. Y., Corchado, J. C., and Truhlar, D. G.: Mapped interpolation scheme for single-point energy corrections in reaction rate calculations and a critical evaluation of dual-level reaction path dynamics methods, J. Phys. Chem. A 103, 1140-1149, 1999.

Corchado, J. C., Chang, Y.-Y., Fast, P. L., Villa, J., Hu, W.-P., Liu, Y.-P., Lynch, G. C., Nguyen, K. A., Jackels, C. F., Melissas, V. S., Lynch, B. J., Rossi, I., Coitino, E. L., Fernandez-Ramos, A., Pu, J.-Z., Albu, T. V., Steckler, R., Garrett, B. C., Isaacson, A. D., and Truhlar, D. G.: POLYRATE version 9.4.1, University of Minnesota, Minneapolis, 2002.

Edney, E. O. and Driscoll, D. J.: Chlorine initiated photooxidation studies of hydrochlorofluorocarbons (HCFCs) and hydrofluorocarbons (HFCs): Results for HCFC-22 $\left(\mathrm{CHClF}_{2}\right)$; HFC-41 (CH3F); HCFC-124 (CClFHCF 3$)$; HFC-125 $\left(\mathrm{CF}_{3} \mathrm{CHF}_{2}\right)$; HFC134a $\left(\mathrm{CF}_{3} \mathrm{CH}_{2} \mathrm{~F}\right)$; HCFC-142b $\left(\mathrm{CClF}_{2} \mathrm{CH}_{3}\right)$; and HFC-152a $\left(\mathrm{CHF}_{2} \mathrm{CH}_{3}\right)$, Int. J. Chem. Kinet., 24, 1067-1081, 1992.

Fantechi, G., Jensen, N. R., Saastad, O., Hjorth, J., and Peeters, J.: Reactions of $\mathrm{Cl}$ atoms with selected VOCs: Kinetics, products and mechanisms, J. Atmos. Chem., 31, 247-267, 1998.

Finlayson-Pitts, B. J.: The tropospheric chemistry of sea salt: A molecular-level view of the chemistry of $\mathrm{NaCl}$ and $\mathrm{NaBr}$, Chem. Rev., 103, 4801-4822, 2003.

Foster, K. L., Plastridge, R. A., Bottenheim, J. W., Shepson, P. B., Finlayson-Pitts, B. J., and Spicer, C. W.: The role of $\mathrm{Br}_{2}$ and $\mathrm{BrCl}$ in surface ozone destruction at polar sunrise, Science, 291, 471-474, 2001.

Francisco, J. S., and Zhao, Y.: The reaction of atomic fluorine with formyl fluoride: An experimental and theoretical study, J. Chem. Phys., 93, 276-286, 1990.

Frisch, M. J., Truck, G. W., Schlegel, H. B., Scuseria, G. E., Robb, M. A., Cheeseman, J. R., Zakrzewski, V. G., Montgomery, J. A., Stratmann, J. R. E., Burant, J. C., Dapprich, S., Millam, J. M., Daniels, A. D., Kudin, K. N., Strain, M. C., Farkas, O., Tomasi, J., Barone, V., Cossi, M., Cammi, R., Mennucci, B., Pomelli, C., Adamo, C., Clifford, S., Ochterski, J., Petersson, G. A., Ayala, P. Y., Cui, Q., Morokuma, K., Malick, D. K., Rabuck, A. D., Raghavachari, K., Foresman, J. B., Cioslowski, J., Ortiz, J. V., Boboul, A. G., Stefnov, B. B., Liu, G., Liaschenko, A., Piskorz, P., Komaromi, L., Gomperts, R., Martin, R. L., Fox, D. J., Keith, T., Al-Laham, M. A., Peng, C. Y., Nanayakkara, A., Gonzalez, C., Challacombe, M., Gill, P. M. W., Johnson, B., Chen, W., Wong, M. W., Andres, J. L., Gonzalez, C., Head-Gordon, M., Replogle, E. S., and Pople, J. A.: Revision A.1, Guassian, Inc., Pittsburgh, PA, GAUSSIAN 03, 2003.

Fu, D. J., Boone, C. D., Bernath, P. F., Walker, K. A., Nassar, R., Manney, G. L., and McLeod, S. D.: Global phosgene observations from the atmospheric chemistry experiment (ACE) mission,
Geophys. Res. Lett., 34, L17815, doi:10.1029/2007GL029942, 2007.

Gonzalez, J., Anglada, J. M., Buszek, R. J., and Francisco, J. S.: Impact of Water on the $\mathrm{OH}$ plus $\mathrm{HOCl}$ Reaction, J. Am. Chem. Soc., 133, 3345-3353, 2011.

Groner, P. and Warren, R. D.: Approximate r(e) structures from experimental rotational constants and ab initio force fields, J. Mol. Struct., 599, 323-335, 2001.

Hammond, G. S.: A correlation of reaction rates, J. Am. Chem. Soc., 77, 334-338, 1955.

Hasson, A. S., Moore, C. M., and Smith, I. W. M.: The fluorine atom initiated oxidation of $\mathrm{CF}_{3} \mathrm{CFH}_{2}$ (HFC-134a) studied by FTIR spectroscopy, Int. J. Chem. Kinet., 30, 541-554, 1998.

Hatakeyama, S. and Leu, M. T.: Rate Constants for Reactions between Atmospheric Reservoir Species .2. $\mathrm{H}_{2} \mathrm{O}$, J. Phys. Chem., 93, 5784-5789, 1989.

Hu, W. P. and Truhlar, D. G.: Factors affecting competitive ionmolecule reactions: $\mathrm{ClO}^{-}+\mathrm{C}_{2} \mathrm{H}_{5} \mathrm{Cl}$ and $\mathrm{C}_{2} \mathrm{D}_{5} \mathrm{Cl}$ via $\mathrm{E} 2$ and $\mathrm{S}_{N} 2$ channels, J. Am. Chem. Soc., 118, 860-869, 1996.

Huisman, P. A. G., Klebe, K. J., Mijlhoff, F. C., and Renes, G. H.: Molecular-structure of formyl fluoride in the gas-phase as determined from electron-diffraction and microwave data, J. Mol. Struct., 57, 71-82, 1979.

Iuga, C., Galano, A., and Vivier-Bunge, A.: Theoretical investigation of the $\mathrm{OH}$-initiated oxidation of benzaldehyde in the troposphere, Chem. Phys. Chem., 9, 1453-1459, 2008.

IUPAC: http://goldbook.iupac.org/I03272.html, last access: March 2013.

Ji, Y. M., Zhao, X. L., Li, Z. S., and Liu, J. Y.: Kinetic mechanism of the hydrogen abstraction reactions of the chlorine atoms with $\mathrm{CH}_{3} \mathrm{CF}_{2} \mathrm{Cl}$ and $\mathrm{CH}_{3} \mathrm{CFCl}_{2}$ : A dual level direct dynamics study, J. Comput. Chem., 28, 975-983, 2007.

Jobson, B. T., Niki, H., Yokouchi, Y., Bottenheim, J., Hopper, F., and Leaitch, R.: Measurements of C2-C6 Hydrocarbons during the Polar Sunrise 1992 Experiment - Evidence for Cl Atom and Br Atom Chemistry, J. Geophys. Res.-Atmos., 99, 25355-25368, 1994.

Libuda, H. G., Zabel, F., Fink, E. H., and Becker, K. H.: Formyl chloride: UV absorption cross sections and rate constants for the reactions with $\mathrm{Cl}$ and OH, J. Phys. Chem., 94, 5860-5865, 1990.

Liu, Y. P., Lu, D. H., Gonzalezlafont, A., Truhlar, D. G., and Garrett, B. C.: Direct dynamics calculation of the kinetic isotope effect for an organic hydrogen-transfer reaction, including cornercutting tunneling in 21 Dimensions, J. Am. Chem. Soc., 115, 7806-7817, 1993.

Manney, G. L., Froidevaux, L., Waters, J. W., Zurek, R. W., Read, W. G., Elson, L. S., Kumer, J. B., Mergenthaler, J. L., Roche, A. E., Oneill, A., Harwood, R. S., Mackenzie, I., and Swinbank, R.: Chemical Depletion of Ozone in the Arctic - Lower Stratosphere during Winter 1992-93, Nature, 370, 429-434, 1994.

Manney, G. L., Santee, M. L., Rex, M., Livesey, N. J., Pitts, M. C., Veefkind, P., Nash, E. R., Wohltmann, I., Lehmann, R., Froidevaux, L., Poole, L. R., Schoeberl, M. R., Haffner, D. P., Davies, J., Dorokhov, V., Gernandt, H., Johnson, B., Kivi, R., Kyro, E., Larsen, N., Levelt, P. F., Makshtas, A., McElroy, C. T., Nakajima, H., Parrondo, M. C., Tarasick, D. W., von der Gathen, P., Walker, K. A., and Zinoviev, N. S.: Unprecedented Arctic ozone loss in 2011, Nature, 478, 469-465, 2011. 
Meagher, R. J., McIntosh, M. E., Hurley, M. D., and Wallington, T. J.: A kinetic study of the reaction of chlorine and fluorine atoms with $\mathrm{HC}(\mathrm{O}) \mathrm{F}$ at $295+/-2 \mathrm{~K}$, Int. J. Chem. Kinet., 29, 619-625, 1997.

Nagai, K., Yamada, C., Endo, Y., and Hirota, E.: Infrared diodelaser spectroscopy of FCO- the NU-1 and NU-2 bands, J. Mol. Spectrosc., 90, 249-272, 1981.

Newman, P. A., Oman, L. D., Douglass, A. R., Fleming, E. L., Frith, S. M., Hurwitz, M. M., Kawa, S. R., Jackman, C. H., Krotkov, N. A., Nash, E. R., Nielsen, J. E., Pawson, S., Stolarski, R. S., and Velders, G. J. M.: What would have happened to the ozone layer if chlorofluorocarbons (CFCs) had not been regulated?, Atmos. Chem. Phys., 9, 2113-2128, doi:10.5194/acp-9-2113-2009, 2009.

NIST: http://webbook.nist.gov/chemistry/, last access: March 2013. Ofner, J., Balzer, N., Buxmann, J., Grothe, H., Schmitt-Kopplin, Ph., Platt, U., and Zetzsch, C.: Halogenation processes of secondary organic aerosol and implications on halogen release mechanisms, Atmos. Chem. Phys., 12, 5787-5806, doi:10.5194/acp-12-5787-2012, 2012.

Orlando, J. J.: Temperature dependence of the rate coefficients for the reaction of chlorine atoms with chloromethanes, Int. J. Chem. Kinet., 31, 515-524, 1999.

Rayez, M. T., Rayez, J. C., and Sawerysyn, J. P.: Ab-Initio Studies of the Reactions of Chlorine Atoms with Fluorosubstituted and Chlorosubstituted Methanes, J. Phys. Chem., 98, 11342-11352, 1994.

Read, K. A., Mahajan, A. S., Carpenter, L. J., Evans, M. J., Faria, B. V. E., Heard, D. E., Hopkins, J. R., Lee, J. D., Moller, S. J., Lewis, A. C., Mendes, L., McQuaid, J. B., Oetjen, H., Saiz-Lopez, A., Pilling, M. J., and Plane, J. M. C.: Extensive halogen-mediated ozone destruction over the tropical Atlantic Ocean, Nature, 453, 1232-1235, 2008.

Riedel, T. P., Bertram, T. H., Crisp, T. A., Williams, E. J., Lerner, B. M., Vlasenko, A., Li, S. M., Gilman, J., de Gouw, J., Bon, D. M., Wagner, N. L., Brown, S. S., and Thornton, J. A.: Nitryl Chloride and Molecular Chlorine in the Coastal Marine Boundary Layer, Environ. Sci. Technol., 46, 10463-10470, 2012.

Rossi, M. J.: Heterogeneous reactions on salts, Chem. Rev., 103, 4823-4882, 2003.

Sanhueza, E. and Heicklen, J.: Chlorine-atom sensitized oxidation of dichloromethane and chloromethane, J. Phys. Chem., 79, 711, 1975.
Solberg, S., Schmidbauer, N., Semb, A., Stordal, F., and Hov, O.: Boundary-layer ozone depletion as seen in the Norwegian Arctic in Spring, J. Atmos. Chem., 23, 301-332, 1996.

Solomon, S.: Stratospheric ozone depletion: A review of concepts and history, Rev. Geophys., 37, 275-316, 1999.

Sommariva, R., and von Glasow, R.: Multiphase Halogen Chemistry in the Tropical Atlantic Ocean, Environ. Sci. Technol., 46, 10429-10437, 2012.

Stanek, L. W., Brown, J. S., Stanek, J., Gift, J., and Costa, D. L.: Air Pollution Toxicology-A Brief Review of the Role of the Science in Shaping the Current Understanding of Air Pollution Health Risks, Toxicol. Sci., 120, S8-S27, 2011.

Truhlar, D. G. and Garrett, B. C.: Variational Transition-State Theory, Acc. Chem. Res., 13, 440-448, 1980.

Truhlar, D. G., Garrett, B. C., and Klippenstein, S. J.: Current status of transition-state theory, J. Phys. Chem., 100, 12771-12800, 1996.

Wallington, T. J., Hurley, M. D., Ball, J. C., and Kaiser, E. W.: Atmospheric chemistry of hydrofluorocarbon 134a: Fate of the alkoxy radical $\mathrm{CF}_{3} \mathrm{CFHO}$, Environ. Sci. Technol., 26, 13181324, 1992.

Wallington, T. J., Hurley, M. D., and Schneider, W. F.: Atmospheric chemistry of $\mathrm{CH}_{3} \mathrm{Cl}$ : Mechanistic study of the reaction of $\mathrm{CH}_{2} \mathrm{ClO}_{2}$ radicals with $\mathrm{HO}_{2}$, Chem. Phys. Lett., 251, 164 $173,1996$.

Wingenter, O. W., Sive, B. C., Blake, N. J., Blake, D. R., and Rowland, F. S.: Atomic chlorine concentrations derived from ethane and hydroxyl measurements over the equatorial Pacific Ocean: Implication for dimethyl sulfide and bromine monoxide, J. Geophys. Res.-Atmos., 110, D20308, doi:10.1029/2005JD005895, 2005.

Wu, H. Y., Liu, J. Y., Li, Z. S., Huang, X. R., and Sun, C. C.: Theoretical study and rate constant calculation for the F+CHFO reaction, Chem. Phys. Lett., 369, 504-512, 2003.

Wu, J. Y., Liu, J. Y., Li, Z. S., Huang, X. R., and Sun, C. C.: Direct $a b$ initio dynamics calculations of the reaction rates for the hydrogen abstraction reaction $\mathrm{Cl}+\mathrm{HC}(\mathrm{O}) \mathrm{F}->\mathrm{HCl}+\mathrm{CFO}$, Phys Chem. Chem. Phys., 4, 2927-2931, 2002.

Zheng, J. J. and Truhlar, D. G.: Kinetics of hydrogen-transfer isomerizations of butoxyl radicals, Phys. Chem. Chem. Phys., 12, 7782-7793, 2010 